\title{
Identification and Characterization of Escherichia coli Isolates in Bovine Mastitis Milk from Bhubaneswar, Odisha, India
}

\author{
Kailash Singh Bisht ${ }^{1}$, Rajashree Mishra ${ }^{1}$, Prasad Kumar Pati ${ }^{2}$, \\ Ritun Patra ${ }^{3}$, Prasana Kumar Rath ${ }^{4}$ and Pravas Ranjan Sahoo ${ }^{5}$
}

${ }^{1}$ Department of Veterinary Microbiology, ${ }^{2}$ Department of Livestock Products Technology,

${ }^{3}$ Department of Veterinary Anatomy\& Histology, ${ }^{4}$ Department of Veterinary Pathology,

${ }^{5}$ Department of Veterinary BiochemistryCollege of Veterinary Science and Animal Husbandry, OUAT, Bhubaneswar, Odisha-751003, India

*Corresponding author

\section{A B S T R A C T}

Escherichia coli is one of the most commonly infecting bacterial etiology of the Bovine mastitis. The coliform mastitis is the most difficult type to

\section{Keywords}

Escherichia coli,

Mastitis,

Antibiogram status

Ofloxacin

Article Info

Accepted:

17 August 2020

Available Online:

10 September 2020 treat due to increase in antibiotic resistance and generally cause recurrent and chronic form of mastitis. Therefore this present study was done to determine the prevalence rate of $E$. coli from the bovine mastitis milk and its antibiogram status. 250 mastitis milk samples were collected from the bovines. $27.2 \%(\mathrm{n}=68) \mathrm{E}$. coli isolates were identified in the samples. The isolated $E$. coli also showed biofilm forming ability in 51 isolates using Congo red agar method. Gentamicin is most sensitive drugs against $E$. coli isolates whereas ampicillin and tetracycline showed highest resistance. For the biofilm forming isolates, gentamicin is most effective whereas ampicillin followed by tetracycline and ofloxacin showed higher ineffectiveness. It was evident that the sessile form of $E$. coli isolates are more resistant to antibiotics compared to their planktonic forms. The multidrug resistance in E. coli isolates was also reported.

\section{Introduction}

The mastitis in bovines is a predominant dairy disease. It results in major economic losses in dairy farms, caused by the decrease in milk yield, increased veterinary cost and increase in culling and mortality (Melchior et al.,
2006). Staphylococci, coliforms, Enterococci and Streptococci are frequently isolated from cows with mastitis (Smulski et al., 2011). It affects the physical, chemical, biological, organo-leptic, bacteriological and other properties of the milk. The loss due to the decrease in milk production and other 
associated losses are more severe in case of subclinical mastitis than those occurred due to clinical cases. Preventing subclinical mastitis in a dairy farm can reduce the losses in milk production. As the annual losses to dairy industry due to mastitis is documented around Rs 7,165 crore in India (Anonymous, 2011). The mastitis milk may accidentally contaminate bulk milk on mixing and enters the food chain which poses a great threat to public health (Hameed et al., 2006).

Biofilm is a complex assemblage formed by single or more species of bacteria that isencased by an exopolysaccharides matrix (Zhu et al., 2009). It is found that many pathogenic veterinary bacteria do exists predominantly as biofilm or sessile organisms within or around animal tissue. It is well recognized by many researchers that biofilm producing infections are extremely difficult to treat (Morck et al., 1989; Sandholm et al., 1990; Baselga et al., 1993 and Potera, 1999). The biofilm formed has been also considered as a virulence factor contributing to persistent infection (Christensen et al., 1982; Arciola et al., 2001). Antibiotic therapy is the main treatment for control of bovine clinical mastitis. Indiscriminate and large scale use of antimicrobials in farm animals leads to considerable increase in antimicrobialresistant strains of bacteria. The antibiotic resistant can increase the treatment cost and period of disease (Sawant et al., 2007). Therefore, the aim of this study was to identify and characterize $E$. coli isolates associated with bovine mastitis milk from area in and around Bhubaneswar, Odisha.

\section{Materials and Methods}

In this study 250 mastitis milk samples collected from lactating cattle $(n=172)$ and buffaloes $(n=78)$ was used. All mastitis milk samples used for the study were referred by field clinicians to either Teaching Veterinary
Clinical Complex (TVCC), C.V.Sc.\&A.H., O.U.A.T or directly received in the department of Veterinary Microbiology for the antimicrobial susceptibility testing. The current study was carried out in the department of Veterinary Microbiology, College of Veterinary Science and Animal Husbandry, Orissa University of Agriculture and Technology, Bhubaneswar.

All the samples were processed according to the Collins and Lyne (1970) for isolation and identification of the E. coli using cultural and biochemical tests. The mastitis milk is inoculated in the brain heart infusion (BHI) broth for primary cultivation of pathogenic bacteria. The MacConkey lactose agar was used for the primary isolation and Eosin Methylene blue agar and biochemical test like indole test, methyl red reduction test, voges Proskauer test, citrate reduction test and triple sugar iron test was done to confirm E.coli. Then all E. coli isolates were screened for their biofilm producing ability by using Congo Red Agarmethod (Cruzado-Bravo et al., 2019).

The ABST for the planktonic and biofilm forming $E$. $\operatorname{coli}(\mathrm{n}=50)$ bacteria isolates was conducted as per Clinical \& Laboratory Standards Institute(CLSI) guidelines (Bauer et al., 1966;Wayne, 2009) with modification as mentioned below. For antibiotic sensitivity testing of biofilm forming isolates, $0.3 \%$ of bentonite clay was added to Mueller-Hinton Agar (MHA), whereas for planktonic isolates bentonite clay was not added as a substrate. The inoculum was prepared by diluting the isolated colony in normal saline with turbidity matched to $0.5 \mathrm{McFarland}$ turbidity standard and swabbed evenly onto the surface of MHA for planktonic growth and MHA $+0.3 \%$ Bentonite clay for biofilm growth. Antibiotic discs were ampicillin $(10 \mathrm{mcg})$, enrofloxacin (10 mcg), erythromycin (15 mcg), ciprofloxacin (5 $\mathrm{mcg})$, 
piperacillin/tazobactam (100/10 mcg), gentamicin $(10 \mathrm{mcg})$, amoxicillin/ clavulanic acid (20/10 $\mathrm{mcg})$, cefoperazone $(75 \mathrm{mcg}$ ), chloramphenicol (30 mcg), doxycycline (10 $\mathrm{mcg})$, ceftriaxone (10 $\mathrm{mcg})$, nalidixic acid (30 $\mathrm{mcg}$ ), ofloxacin (5 mcg), streptomycin (10 $\mathrm{mcg})$ and tetracycline $(30 \mathrm{mcg})$. All the antibiotic discs were procured from HiMedia, Mumbai. Antibiotic sensitivity test (ABST) plates were incubated for $18-24 \mathrm{hrs}$ at $37{ }^{\circ} \mathrm{C}$. The results of the ABST were interpreted according to guidelines of the Clinical and Laboratory Standards Institute (CLSI) (Wayne, 2009).

\section{Results and Discussion}

All results of E. coli screening, their biochemical testing, detection of biofilm producing ability and antimicrobial susceptibility testing for bacterial isolates were studied. In this study, $68 \mathrm{E}$. coli isolates were isolated from the 250 bovine mastitis milk samples. Out of total E. coli isolates, $42.65 \%(\mathrm{n}=29)$ of $E$. coli were isolated from buffaloes milk sample and $57.35 \%(\mathrm{n}=39)$ were isolated from cattle milk samples. Gram's stain of E. coli shown in figure 1. The biochemical characteristics of E. coli tested were given in the table 1 . On screening of the biofilm formation by $E$. coli isolates using the
Congo red agar method showed $75 \%(n=51)$ of $E$. coli isolates as positive for biofilm production and $25 \%(\mathrm{n}=17)$ of $E$. coli isolates were found negative.

The antibiotic sensitivity test results for planktonic form of E. coli isolates using 15 antibiotics showed that the most sensitive antibiotic against $E$. coli is gentamicin followed by chloramphenicol, cefoperazone, ceftriaxone, ciprofloxacin, erythromycin, enrofloxacin, doxycycline, amoxiclav, nalidixic acid, ofloxacin and streptomycin,. Whereas the most resistant drug against $E$. coli isolates is ampicillin and tetracycline. The results of antibiotic sensitivity test for sessile form of $E$. coli isolates showed gentamicin followed by erythromycin, ceftriaxone, cefoperazone and doxycycline as most effective antibiotic whereas the higher degree of resistance was shown against ampicillin followed by tetracycline and ofloxacin. The antibiotic sensitivity test results for the planktonic and the sessile form of $E$. coli isolates was given in table 2. The multidrug resistance was also shown by the bovine mastitis milk associated $E$. coli isolates which further increases in the case of biofilm formation. There is no specific resistance pattern for the multidrug resistance by these $E$. coli isolates.

Table.1 Biochemical characterization of E. coli isolated from mastitis milk

\begin{tabular}{|c|c|c|}
\hline Test & Reaction & Positive \\
\hline Gram stain & Gram negative bacilli & $100 \%$ \\
\hline \multicolumn{3}{|c|}{ Biochemical identification test } \\
\hline Indole & Red ring & $100 \%$ \\
\hline Methyl red & Red colour & $100 \%$ \\
\hline Voges proskauer & Negative & $0 \%$ \\
\hline Simmon's citrate & Negative & $0 \%$ \\
\hline Catalase & Gas bubbles & $100 \%$ \\
\hline Triple sugar iron & $\mathrm{A} / \mathrm{A} / \pm / \mathrm{H}_{2} \mathrm{~S}-$ & $100 \%$ \\
\hline
\end{tabular}


Table.2 Depicts the comparative percentage of susceptibility shown by both planktonic and biofilm forming bovine mastitis $E$. coli isolates (n= 50isolates), to different antibiotics

\begin{tabular}{|l|l|l|l|l|l|l|}
\hline \multirow{2}{*}{ Antibiotics } & \multicolumn{5}{l}{ Planktonic E. coli (n= 50) (\%) } & \multicolumn{3}{l|}{ Sessile E. coli (n= 50) (\%) } \\
\cline { 2 - 7 } & S & I & R & S & I & R \\
\hline Ofloxacin & 66 & 24 & 10 & 42 & 16 & 42 \\
\hline Ciprofloxacin & 84 & 10 & 6 & 70 & 10 & 20 \\
\hline Gentamicin & 96 & 4 & 0 & 88 & 8 & 4 \\
\hline Streptomycin & 70 & 16 & 14 & 20 & 44 & 36 \\
\hline Tetracycline & 58 & 12 & 30 & 24 & 28 & 48 \\
\hline Chloramphenicol & 82 & 14 & 4 & 72 & 8 & 20 \\
\hline Amoxicillin/ Clavulanic acid & 74 & 6 & 20 & 22 & 44 & 34 \\
\hline Enrofloxacin & 70 & 14 & 16 & 64 & 8 & 28 \\
\hline Erythromycin & 86 & 0 & 14 & 78 & 6 & 16 \\
\hline Ceftriaxone & 82 & 8 & 10 & 78 & 6 & 16 \\
\hline Cefoperazone & 86 & 10 & 4 & 80 & 4 & 16 \\
\hline Nalidixic acid & 70 & 16 & 14 & 66 & 6 & 28 \\
\hline Ampicillin & 54 & 14 & 32 & 8 & 26 & 66 \\
\hline Piperacillin/ Tazobactam & 76 & 2 & 22 & 28 & 36 & 36 \\
\hline Doxycycline & 84 & 0 & 16 & 76 & 6 & 18 \\
\hline
\end{tabular}

Figure.1 E. coli on gram's staining

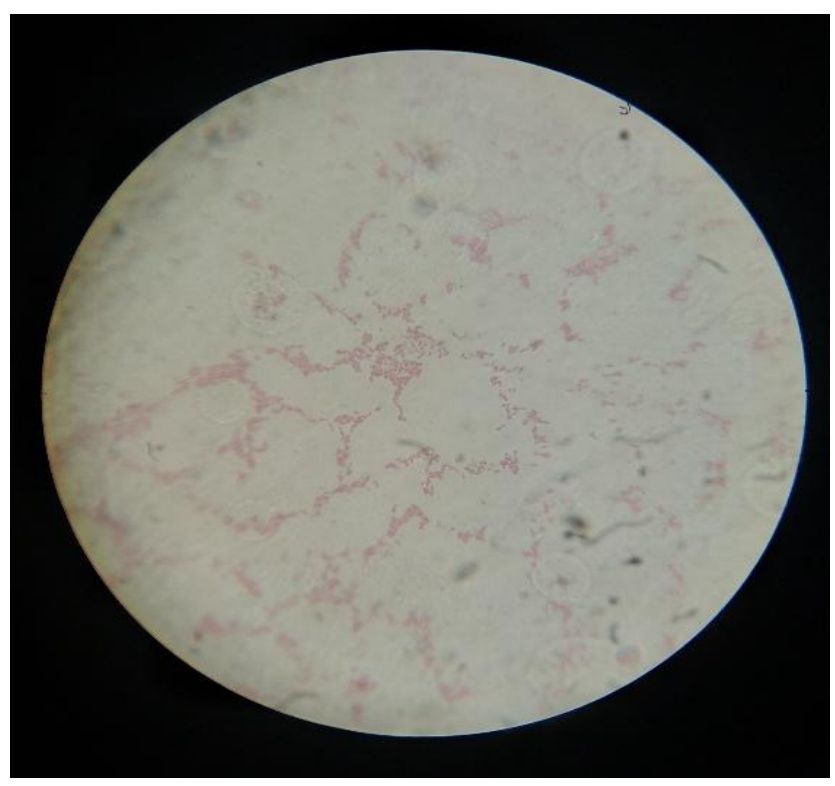


Figure.2 Chart depicting comparative antibiotic resistance between planktonic and sessile form of $E$. coli isolates of bovine mastitis milk

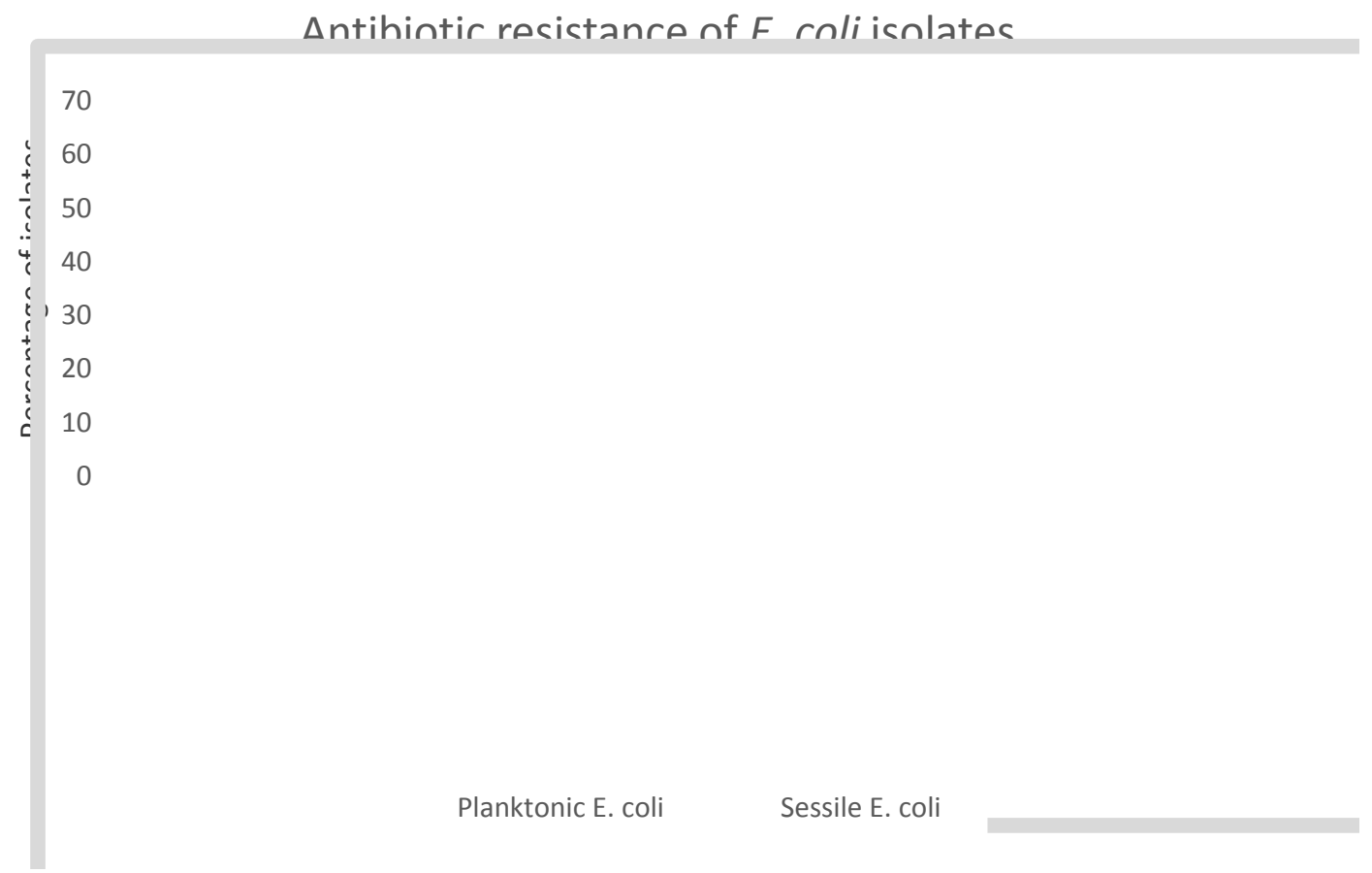

In the present study, the prevalence rate of the E. coli infection in 250 bovine mastitis milk samples was found to be $27.2 \%(n=68)$. This isolation rate is in agreement with the findings of Momtaz et al., (2012) with $27.23 \%$ and Rafik et al., (2014) with $25.5 \%$ isolation rate of $E$. coli. The $75 \%(\mathrm{n}=51)$ of $E$. coli showed positive result to form biofilm on Congo red agar assay. Other researchers, like Parussolo et al., (2019), Cengiz et al., (2014) and Chen et al., (2010) also found comparable results of biofilm formation by total E. coli from different sources to be around $67.52 \%, 67.8 \%$ and $76.56 \%$ positivity respectively.

On antibiotic sensitivity testing, the high susceptibility to gentamicin and chloramphenicol is in agreement with Charaya et al., (2014). The high antibiotic resistance level of $E$. coli to ampicillin and tetracycline is in agreement with the finding of Zhao et al., (2001), Lira et al., (2004) and Rangel and Marin, (2009). The biofilm producing bacterial isolates were said to be up to 1000 time more resistant to antimicrobial agents in comparison to their planktonic counterparts (Costerton et al., 1999; Nickel et al., 1985). Therefore the antibiogram of the biofilm producing E. coli isolates were also done. As mentioned before, the resistance of the biofilm forming E. coli isolates against the antibiotics was much higher compared to planktonic isolates also evident in this study. This finding was in line with the finding of Abdul-Ratha and Nadhom (2014).

The growing multidrug resistance against antimicrobials by the bacteria was a great concern threating the health industry whether it is veterinary or human health. The extent of multidrug resistance is increased many fold by biofilm forming $E$. coli isolates compared to planktonic forms. All these biofilm forming of $E$. coli isolates were resistant to at least one antibiotic used for antibiotic susceptibility testing. 
Ii is concluded, as bovine mastitis is a most prominent problem in dairy industry which is responsible for many herd level and foodborne public health outbreaks. The two main route for foodborne human infection from dairy source are through either contamination by mastitis milk or faecal matter of bovine or ruminant sources. As the E. coli is one of the important pathogen for the bovine mastitis.

The higher incidence of mastitogenic E. coli isolates may be due to poor hygienic dairy practices, unsanitary condition and no personal hygiene. As the E. coli causing mastitis are mainly from environmental sources as an indicator of faecal contamination.

In some recent studies, it has been found that the antibiotic resistance of $E$. coli bacteria in the sessile (i.e., biofilm forming) mode of growth contributes to the reoccurrence and chronicity of mastitis. It was found that the biofilm producing isolates are more resistant and can easily survive the effect of a particular antibiotic than their planktonic counterparts (Figure 2). Therefore, based on the present study the we recommend relevant awareness program on best dairy practice and milk handling should be organized for dairy farmers to control contamination of milk and milk products and there need for investigation of other sources of $E$. coli infection, incidence rate with respect to different seasons, cycle of lactation, age and geographical distribution in Bhubaneswar along with change in milk production of affected cattle.

\section{Conflict of interest}

There is no conflict of interest.

\section{Acknowledgement}

The authors are thankful to the ViceChancellor, Odisha University of Agriculture
\& Technology, Bhubaneswar for providing necessary facilities to conduct the present test.

\section{References}

Abdul-Ratha, H. A. and Nadhom, B. N. 2014. Detection of Biofilm Formed by $E$. coli Isolated from various animal diseases and evaluate it's protective role. International Journal of Current Microbiology and Applied Sciences. 3(9): 902-912.

Anonymous. 2011. http://www.tribuneindia.com/2:326328.2011/20110825/ldh1.html.

Arciola, C. R., Baldassarri, L. and Montanaro, L. 2001. Presence of icaA and icaD genes and slime production in a collection of Staphylococcal strains from catheter associated infections. Journal of clinical microbiology. 39(6): 2151-2156.

Baselga, R., Albizu, I., De la Cruz, M., Del Cacho, E., Barberan, M. and Amorena, B. 1993. Phase variation of slime production in Staphylococcus aureus: implications in colonization and virulence. Infection and Immunity. 61: 4857- 4862.

Bauer, A. W., Kirby, W. M. M., Sherris, J. C. and Jurek, M., 1966. Antibiotic susceptibility testing by a standardized single method. American Journal of Clinical Pathology. 45: 493-496.

Cengiz, S., Dinç, G. and Söğüt, M. Ü.2014. Detection of several virulence properties, antibiotic resistance and phylogenetic relationship in $E$. coli isolates originated from cow mastitis. Acta Veterinaria-Beograd. 64 (4): 413 425.

Charaya G. C., Sharma, A., Kumar, A., Singh, M. and Goel, P. 2014. Pathogens isolated from clinical mastitis in Murrah buffaloes and their antibiogram: Veterinary World. 7(11): 980-985.

Chen, C., Liao, X., Jiang, H., Zhu, H., Yue, 
L., Li, Shujuan., Fang, B. and Liu, Y. 2010. Characteristics of Escherichia coli biofilm production, genetic typing, drug resistance pattern and gene expression under aminoglycoside pressures. Environmental Toxicology and Pharmacology.30: 5-10.

Christensen, G. D., Simpson, W. A., Bisno, A. L. and Beachey, E. H. 1982. Adherence of slime producing strains of Staphylococcus epidermidis to smooth surfaces. Infection and Immunity. 37:318-26.

Collins, C. H. and Lyne, P. M. 1970. Microbiological Methods Laboratory Techniques Series, 4th ed. (Butterworth, London, 1970)

Costerton, J. W., Stewart, P. S. and Greenberg, E. P. 1999. Bacterial biofilms: a common cause of persistent infections. Science. 284: 1318-1322.

Cruzado-Bravo, M. L. M., Silva, N. C. C., Rodrigues, M. X., Silva, G. O. E., Porto, E.et al., 2019. Phenotypic and genotypic characterization of Staphylococcus spp. isolated from mastitis milk and cheese processing: Study of adherence and biofilm formation. Food Research International. 122: $450-460$.

Hameed, K. G. A., Grazyna, S. and Kossakowska, A. K. 2006. Public health hazard due to mastitis in dairy cows. Animal science papers and reports. 25: 73-85.

Lira, W. M., Macedo, C. and Marin, J. M. 2004. The incidence of Shiga toxinproducing Escherichia coli in cattle with mastitis in Brazil. Journal of Applied Microbiology.97: 861-866.

Melchior, M. B., Vaarkamp, H. and FinkGremmels, J. 2006. Biofilms: a role in recurrent mastitis infections? Veterinary Journal. 171:398-407.

Momtaz, H., Dehkordi, F. S., Taktaz, T., Rezvani, A. and Yarali, S. 2012. Shiga
Toxin-Producing Escherichia coli Isolated from Bovine Mastitic Milk: Serogroups, Virulence Factors, and Antibiotic Resistance Properties. The Scientific World Journal. Volume 2012, 9 pages. doi:10.1100/2012/618709.

Morck, D. W., Olson, M. E., Acres, S. D., Daoust, P. Y., Costerton, J.W. 1989. Presence of bacterial glycocalyx and fimbriae on Pasteurella haemolytica in feedlot cattle with pneumonic pasteurellosis. Canadian Journal of Veterinary Research.53:167-171.

Nickel, J. C., Ruseska, I., Wright, J. B. and Costerton, J. W. 1985. Tobramycin resistance of Pseudomonas aeruginosa cells growing as a biofilm on urinary catheter material. Antimicrobial Agents and Chemotherapy. 27: 619-24.

Parussolo, L., Sfaciotte, R. A. P., Dalmina, K. A., Melo, F. D., Costa, U. M. and Ferraz, S. M. 2019. Detection of virulence genes and antimicrobial resistance profiles of Escherichia coli isolates from raw milk and artisanal cheese in Southern Brazil. Semina: Ciências Agrárias, Londrina. 40(1): 163-178.

Potera, C. 1999. Forging a link between biofilms and disease. Science. 283: 1837-1838.

Rafik, H. S., Selim, S. S. and Rafik, T. S. 2014. Bacteriological Evaluation of Present Situation of Mastitis in Dairy Cows.Global Veterinaria.13(5): 690695.

Rangel. P. and Marin, J. M. 2009, Analysis of Escherichia coli isolated from bovine mastitic milk. Pesquisa Veterinária Brasileira.29:363-368.

Sandholm, M., Kaartinenm L. and Pyorala, S. 1990. Bovine mastitis - Why does antibiotic therapy not always work? An overview. Journal of Veterinary Pharmacology and Therapeutics. 13: 248-260. 
Sawant, A. A., Hegde, N. V., Straley, B. A., Donaldson, S. C., Love, B. C., Knabel, S. J. and Jayarao, B. M. 2007. Antimicrobial-resistant enteric bacteria from dairy cattle. Applied and Environmental Microbiology. 73: 156163.

Smulski, S., Malinowski, E., Kaczmarowski, M. et al., (2011). Occurrence, forms and etiologic agents of mastitis in Poland depending on size of farm. Medycyna Weterynaryjna-Veterinary MedicineScience and Practice. 67:190-3.

Wayne, P. A., 2009. Clinical and Laboratory Standards Institute (CLSI) Performance Standards for Antimicrobial Disk Diffusion Susceptibility Tests. 19th edn., approved standard, CLSI document., M100-S19.
Zhao, S., White, D. G., McDermott, P. F., Friedman, S., English, L., Ayers, S., Meng, J., Maurer, J. J., Holand, R. and Walker, R. D. 2001. Identification and expression of cephamycinase bla CMY genes in Escherichia coli and Salmonella isolates from food animals and ground meat. Antimicrobial Agents and Chemotherapy. 45:3647-3650.

Zhu, Y. F., Xiong, Y. Q., Sadykov, M. R., Fey, P. D., Lei, M. G., Lee, C. Y., Bayer, A. S. and Somerville, G. A. 2009. Tricarboxylic acid cycledependent attenuation of Staphylococcus aureus in vivo virulence by selective inhibition of amino acid transport. Journal of Infection and Immunity. 77(10): 4256-4264.

\section{How to cite this article:}

Kailash Singh Bisht, Rajashree Mishra, Prasad Kumar Pati, Ritun Patra, Prasana Kumar Rath and Pravas Ranjan Sahoo. 2020. Identification and Characterization of Escherichia coli Isolates in Bovine Mastitis Milk from Bhubaneswar, Odisha, India. Int.J.Curr.Microbiol.App.Sci. 9(09): 2088-2095. doi: https://doi.org/10.20546/ijcmas.2020.909.260 